American Journal of Applied Sciences 4 (12): 1090-1093, 2007

ISSN 1546-9239

(C) 2007 Science Publications

\title{
Gamma Radiosensitivity Study on Long Bean (Vigna sesquipedalis)
}

\author{
Ellyfa Kon, Osumanu Haruna Ahmed, Shaharudin Saamin and Nik Muhamad Ab. Majid \\ Department of Crop Science, Faculty of Agriculture and Food Sciences, \\ Universiti Putra Malaysia Bintulu Campus, Sarawak, 97008 Bintulu, Sarawak, Malaysia
}

\begin{abstract}
This study was conducted to determine the $\mathrm{LD}_{50}$ and effect of gamma ray on germination percentage, plant height, survival percentage, root length, root dry weight and shoot dry weight of seedlings derived from seeds of long bean (Vigna sesquipedalis). Seeds of this crop were treated with 300, 400, 500, 600 and $800 \mathrm{~Gy}$ gamma rays at Malaysian Institute of Nuclear Technology (MINT). The treated seeds including control were sown in sand beds in size $4.6 \times 0.7 \mathrm{~m}^{2}$ in a greenhouse at Horticulture Unit, Universiti Putra Malaysia Bintulu Campus (UPMKB). After germination, plants were transferred into polybags. Each polybag contained $1.2 \mathrm{~kg}$ blended growth medium with top soil, sand, and processed chicken dung ratio of 3:2:1. Standard procedures were used to observe and record the variables studied in this research. The experiment was designed as a $4 \times 6$ factorial Completely Randomized Design with 3 replications. Lethal dose $50 \%$ of population $\left(\mathrm{LD}_{50}\right)$ was assayed. The study revealed that germination percentage, plant height, survival percentage, root length, root dry weight and shoot dry weight decreased with increasing dose of gamma ray. The 800 Gy gamma ray dose in particular had a pronounced effect on these morphological characteristics probably because of injury it might have caused to the seeds of the long bean. As a result, poor growth and development was noticed. The $\mathrm{LD}_{50}$ for survival and height ranged between 600-800 Gy and 400-500 Gy, respectively. Generally, higher gamma ray doses particularly 800 Gy significantly affected the morphological characteristics of long bean seedlings obtained from irradiated seeds.
\end{abstract}

Key words: Gamma rays, induced mutation, long bean, Malaysia

\section{INTRODUCTION}

Mutation means a sudden heritable change in the genetic material at the gene or chromosome level ${ }^{[1]}$. They may be caused by error during cell division or by exposure to the DNA-damaging agents or mutagens in the environment. A wide range of characters which have been improved through induced mutation breeding include plant architecture, yield, flowering and maturity duration, quality and tolerance to biotic and abiotic stresses. About $89 \%$ of mutant varieties have been developed using physical mutagens such as X-rays, gamma rays, thermal and fast neutrons where as with gamma rays alone accounting for the development of $60 \%$ of the mutant varieties ${ }^{[2]}$.

Many new cultivars have been directly or indirectly derived through mutation induction and the number of mutant varieties officially released and recorded in the FAO/IAEA MVD before the end of the year 2000 was
$2,252{ }^{[3]}$. The cumulative number of officially released mutant varieties in the world indicates that Asia tops the rest of the continents ${ }^{[2]}$. However, it must be stressed there is only a few mutation breeding studies on long bean (native of Southeast Asia) though the economic significance of this crop cannot be overemphasized as it is widely grown in for instance in Southeast Asia (including Malaysia and Thailand) and Southern China for living. Among the reasons for the modest research on this crop are lack of systematic breeding work and the fact most cultivars grown by farmers are land strains with substantial amount of variability. But with appropriate exposure doses on long bean seeds to ionizing irradiation such as gamma rays which are known for their simple application, good penetration, reproducibility, high mutation frequency and less disposal problems ${ }^{[1]}$, this crop may undergo desirable mutation that could be of significant benefit to agriculture. The aim of this study was to determine the $\mathrm{LD}_{50}$ and effect of gamma ray on

Corresponding Author: Osumanu Haruna Ahmed, Department of Crop Science, Faculty of Agriculture and Food Sciences, Universiti Putra Malaysia Bintulu Campus, Sarawak, Malaysia Tel: +6086855406, Fax: +608685415 
germination percentage, plant height, survival percentage, root length, root dry weight and shoot dry weight of seedlings derived from seeds of long bean (Vigna sesquipedalis).

\section{MATERIALS AND METHODS}

This study was conducted at the Horticulture Unit of Universiti Putra Malaysia Bintulu Campus (UPMKB). Long bean (Vigna sesquipedalis) seeds were obtained from Malaysia Agricultural Research and Development Institute (MARDI). The moisture content of the seeds was measured using Moisture Analyzer (AND MX - 50) at the Agrotechnology Laboratory, UPMBK. Seeds of long bean were treated with 300, 400, 500, 600 and 800 Gy gamma rays at Malaysian Institute of Nuclear Technology (MINT). These treatments were used because treatments such as 50, 100, 150, 200 and $250 \mathrm{~Gy}$ in our previous trial did not produce good results. For each dose, 90 seeds were treated.

Preparation of sand beds was done 2 days before planting where grasses and debris in the sand beds were removed. An insecticide called Ridsect was sprayed around and inside the sand beds to ensure they were free from pests. To ensured good anchorage and adequate retention of nutrients and water, a blended growth medium with a ratio of 3:2:1 (topsoil: sand: processed chicken dung) was used. The sand beds were watered to field capacity to ensure they were moist and loose enough for planting. The treated seeds were sown $(1 \mathrm{~cm}$ depth) in the sand beds in size $4.6 \times 0.7 \mathrm{~m}^{2}$ in a greenhouse at Horticulture Unit, UPMKB. The planting distance was 2 $\mathrm{cm}$ within row and $5 \mathrm{~cm}$ between rows. Water was applied manually to maintain the soil moisture at field capacity as well as weed was manually controlled.

Data on seed germination were collected four times starting from the first day of emergence of the plant's cotyledon from the growth medium surface. Afterwards, 10 plants for each treatment were transferred into polybags. Each polybag contained $1.2 \mathrm{~kg}$ blended growth medium with top soil, sand, and processed chicken dung ratio of 3:2:1.Watering was also done daily and plant growth was monitored until 45 days after planting.

Data on germination, seedling height, survival percentage, root length, root dry weight and shoot dry weight were recorded. Seedling height was measured by the flat method ${ }^{[4]}$. For every 4 days, seedling height was measured from the surface of the planting medium to the shoots of the plants using a ruler. This measurement was done when the first leaf had stopped growing ${ }^{[4]}$. The measurement started from day 6 after planting to 18 days after planting (DAP). Root length measurement was done at 45 DAP. Roots were separated by gently washing away the growth medium with water. Plants were partitioned into root and shoot after which root length was determined using a ruler. Afterwards, these plant parts were bagged in brown paper bags and oven dried at $60{ }^{\circ} \mathrm{C}$ until constant weight was attained. The plants that survived at harvest were counted. Lethal dose $50 \%$ of population $\left(\mathrm{LD}_{50}\right)$ was assayed.

The experiment was designed as a $4 \times 6$ factorial in Completely Randomized Design (CRD) with three replications. Means in each treatment were compared by Tukey's Test using Statistical Analysis System Version 9.1 (SAS).

\section{RESULTS AND DISCUSSION}

The moisture content of the long bean seed was 7.21 $\%$. There was no interaction between dose and time (Table 1). Dose as a factor also did not affect long bean seed germination although time had significant effect on germination.

The data in Table 2 indicates that all the doses consistently reduced long bean height compared to the control. Plant height significantly decreased with increasing dosage with 800 Gy having the most pronounced effect. Compared to the control, only $600 \mathrm{~Gy}$

Table 1: Germination percentage (\%) of irradiated long bean seeds with $0,300,400,500,600$ and 800 Gy gamma rays after planting for $3,4,5$ and 6 days

\begin{tabular}{|c|c|c|c|c|c|}
\hline \multirow[b]{2}{*}{ Dose } & \multicolumn{4}{|c|}{ DAP } & \multirow[b]{2}{*}{ Dose factor } \\
\hline & 3 & 4 & 5 & 6 & \\
\hline \multicolumn{2}{|c|}{$\begin{array}{l}\text { Control } \\
\quad 76.95^{\mathrm{a} "}\end{array}$} & 55.56 & 71.11 & 88.89 & 92.22 \\
\hline \multicolumn{2}{|c|}{$\begin{array}{l}300 \mathrm{~Gy} \\
77.78^{\mathrm{a}}\end{array}$} & 57.78 & 71.11 & 91.11 & 91.11 \\
\hline \multicolumn{2}{|c|}{$\begin{array}{l}400 \text { Gy } \\
76.39^{a "}\end{array}$} & 51.11 & 72.22 & 88.89 & 93.33 \\
\hline \multicolumn{2}{|c|}{$\begin{array}{l}500 \mathrm{~Gy} \\
\quad 71.39^{\mathrm{a}}\end{array}$} & 56.67 & 68.89 & 78.89 & 81.11 \\
\hline \multicolumn{2}{|c|}{$\begin{array}{l}600 \mathrm{~Gy} \\
76.67^{\mathrm{a}}\end{array}$} & 60.00 & 77.78 & 82.22 & 86.67 \\
\hline \multicolumn{2}{|c|}{$\begin{array}{l}800 \mathrm{~Gy} \\
70.56^{\mathrm{a}}\end{array}$} & 54.45 & 70.00 & 77.78 & 80.00 \\
\hline Time fa & & $55.93^{\mathrm{c}}$ & $71.85^{\mathrm{b}^{\prime}}$ & $84.63^{\mathrm{a}^{\mathrm{\prime}}}$ & $87.41^{\mathrm{a}^{\mathrm{z}}}$ \\
\hline
\end{tabular}


Means without letters in column are not statistically different between treatments by the Tukey test $(\mathrm{p}=0.05)$. Mean of time factor, "Mean of dose factor. DAP means days after planting

Table 2: Height (cm) of irradiated long bean seeds with $0,300,400$, 500,600 and 800 Gy gamma rays after planting for $6,10,14$ and 18 days

\begin{tabular}{|c|c|c|c|c|c|}
\hline \multirow[b]{3}{*}{ Control } & \multicolumn{4}{|l|}{ DAP } & \multirow[b]{2}{*}{ Dose factor } \\
\hline & 6 & 10 & 14 & 18 & \\
\hline & $11.96^{\mathrm{a}}$ & $18.99^{\mathrm{a}}$ & $21.68^{\mathrm{a}}$ & $25.81^{\mathrm{a}}$ & $19.41^{\mathrm{a} "}$ \\
\hline 300 Gy & $8.92^{\mathrm{b}}$ & $13.10^{\mathrm{b}}$ & $15.25^{\mathrm{b}}$ & $16.14^{b}$ & $13.35^{\mathrm{b} "}$ \\
\hline $400 \mathrm{~Gy}$ & $7.01^{\mathrm{c}}$ & $8.89^{\mathrm{c}}$ & $13.38^{b c}$ & $14.22^{\mathrm{bc}}$ & $10.87^{\mathrm{c} "}$ \\
\hline $500 \mathrm{~Gy}$ & $5.54^{\mathrm{d}}$ & $6.77^{\mathrm{d}}$ & $11.33^{\mathrm{c}}$ & $11.73^{\mathrm{cd}}$ & $8.84^{\mathrm{d}^{\mathrm{d}}}$ \\
\hline $600 \mathrm{~Gy}$ & $3.93^{\mathrm{e}}$ & $4.86^{\mathrm{de}}$ & $10.57^{\mathrm{c}}$ & $11.58^{\mathrm{cd}}$ & $7.74^{\mathrm{e} "}$ \\
\hline $800 \mathrm{~Gy}$ & $2.52^{\mathrm{f}}$ & $3.80^{\mathrm{e}}$ & $7.54^{\mathrm{d}}$ & $9.14^{\mathrm{d}}$ & $5.75^{\mathrm{f}^{\prime}}$ \\
\hline Time factor & $\mathrm{r} \quad 6.51^{\mathrm{d}^{\prime}}$ & $9.40^{c^{\prime}}$ & $13.29^{b^{\prime}}$ & $14.77^{\mathrm{a}}$ & \\
\hline
\end{tabular}

Means with different letter(s) in column are statistically different between treatments by the Tukey test $(\mathrm{p}=0.05)$. 'Mean of time factor, "Mean of dose factor. DAP means days after planting

Table 3: Root length of irradiated long bean seeds with $0,300,400,500$, 600 and 800 Gy gamma rays after planting for 45 days

\begin{tabular}{lc}
\hline Treatment & Root length $(\mathrm{cm})$ \\
\hline Control & $15.20^{\mathrm{a}}$ \\
$300 \mathrm{~Gy}$ & $10.00^{\mathrm{ab}}$ \\
$400 \mathrm{~Gy}$ & $9.30^{\mathrm{ab}}$ \\
$500 \mathrm{~Gy}$ & $8.91^{\mathrm{ab}}$ \\
$600 \mathrm{~Gy}$ & $7.33^{\mathrm{b}}$ \\
$800 \mathrm{~Gy}$ & $3.64^{\mathrm{b}}$ \\
\hline
\end{tabular}

Means with different letters are statistically different between treatments by the Tukey test $(\mathrm{p}=0.05)$

Table 4: Root dry weight and shoot dry weight of irradiated long bean seeds with $0,300,400,500,600$ and 800 Gy gamma rays after planting for 45 days

\begin{tabular}{lcc}
\hline Treatment & Root $(\mathrm{g})$ & Shoot $(\mathrm{g})$ \\
\hline Control & $0.07^{\mathrm{a}}$ & $0.57^{\mathrm{a}}$ \\
$300 \mathrm{~Gy}$ & $0.06^{\mathrm{ab}}$ & $0.38^{\mathrm{ab}}$ \\
$400 \mathrm{~Gy}$ & $0.04^{\mathrm{ab}}$ & $0.31^{\mathrm{bc}}$ \\
$500 \mathrm{~Gy}$ & $0.04^{\mathrm{bc}}$ & $0.17^{\mathrm{bcd}}$ \\
$600 \mathrm{~Gy}$ & $0.01^{\mathrm{cd}}$ & $0.12^{\mathrm{cd}}$ \\
$800 \mathrm{~Gy}$ & $0.01^{\mathrm{d}}$ & $0.05^{\mathrm{d}}$ \\
\hline
\end{tabular}

Means with different letters in column are statistically different between treatments by the Tukey test $(\mathrm{p}=0.05)$

Table 5: Survival percentage of irradiated long bean seeds with 0, 300, $400,500,600$ and 800 Gy gamma rays after planting for 45 days

\begin{tabular}{ll}
\hline Treatment & Survival (\%) \\
\hline Control & $73.33^{\mathrm{a}}$ \\
$300 \mathrm{~Gy}$ & $60.00^{\mathrm{ab}}$ \\
$400 \mathrm{~Gy}$ & $66.67^{\mathrm{ab}}$ \\
$500 \mathrm{~Gy}$ & $43.33^{\mathrm{bc}}$ \\
$600 \mathrm{~Gy}$ & $43.33^{\mathrm{bc}}$ \\
$800 \mathrm{~Gy}$ & $23.33^{\mathrm{c}}$ \\
\hline
\end{tabular}

Means with different letters are statistically different between treatments by the Tukey test $(\mathrm{p}=0.05)$

and 800 Gy significantly reduced the root length of long bean (Table 3). However, with the exception of $300 \mathrm{~Gy}$, the seeds treated with 400, 500, 600 and 800 Gy significantly reduced shoot dry weight (compared to control) particularly 600 and 800 Gy (Table 4). Similar observation was made for root dry weight except that the effects of 300 and 400 Gy were not different from that of the control ((Table 4). This observation suggests that dry matter production of long bean reduces with increasing gamma-ray radiation.

Compared to the control, Table 5 shows that the survival of the long bean was significantly reduced when the irradiation was above $400 \mathrm{~Gy}$. Among the doses, 800 Gy had a pronounced effect on the survival rate of this plant.

The seed moisture content did not compare well with the standard range of 12 and $14 \%$ but the low moisture content did not affect the radiosensitivity of treatments. This was evident in the morphological variables studied. The absence of interaction between time and dose suggest that these 2 factors acted independently. The lower percentage germination at 800 Gy might have caused injury to the seeds and this may have prevented them from germinating well. The differences in germination percentage because of the different treatments was expected as several metabolic events that are known to occur during germination differ in their timing, both among the various organs of a particular seed and among seeds of different species ${ }^{[5,6,7]}$.

The height reduction caused by the doses was consistent with the findings of ${ }^{[2]}$ who reported that reduction of plant heights belongs to the most frequently arising types in mutation experiment. In a similar study, dwarf or shorter plant height of snap bean was found ${ }^{[2]}$. The reduction in root length with increasing dose also partly explains the reduction in plant height as these two variables are interrelated. The reduction in root length observed in this study was comparable with findings of several studies ${ }^{[8,9]}$. The low dry matter production (root and shoot) in this study with increasing dose of gamma radiation relates to the reduction in plant height, shoot, and root length. For instance, good rooting system is characterized by efficient use of water and nutrients which in turn leads to good plant growth and development ${ }^{[10]}$.

The fact that 600 and 800 Gy significantly affected the survival of the snap bean plants compared to the plants of the other treatments including control suggests that snap beans may not survive with time if their seeds are exposed to high gamma radiations.

The $\mathrm{LD}_{50}$ for germination could not be determined in this study and this observation was in agreement with the work of ${ }^{[11]}$ who could not determine $\mathrm{LD}_{50}$ for germination 
because of no significant difference in treatments effect. The $\mathrm{LD}_{50}$ of plant height showed growth reduction of seedling height. The $\mathrm{LD}_{50}$ for long bean survival ranged between 400 and $500 \mathrm{~Gy}$.

\section{CONCLUSIONS}

Increasing gamma ray dose decreased germination percentage, plant height, survival percentage, root length, root dry weight, and shoot dry weight of long bean. The $\mathrm{LD}_{50}$ for survival and height ranged between $600-800 \mathrm{~Gy}$ and 400-500 Gy, respectively. In general, higher gamma ray doses particularly 800 Gy had negative effect on the morphological characteristics of long bean seedlings derived from irradiated seeds.

\section{REFERENCES}

1. Chahal, G.S. and S.S. Gosal, 2002. Principles and Procedures of Plant Breeding. pp. 399-412. Oxford: Alpha Science International Ltd..

2. Kharkwal, M.C., 2000. Induced mutations in chickpea (Cicer arietinum L.) IV. Types of macromutations induced. Indian J. Genet., 60: 305320.

3. Maluszynski, M., K. Nichterlein, L. Van Zanten and B.S Ahloowalia, 2000. Officially Released Mutant Varieties - The FAO/IAEA Database. Mutation Breeding Review, 12: 1-84.
4. FAOSTAT., 1977. Food Agriculture Organization of the United Nations, Production Statistics. On the World Wide Web (http://apps.fao.org).

5. Mayer, A.M. and A. Poljakoff-Mayber, 1989. The Germination of Seeds, Fourth Edition. London: Pergamon.

6. Bewley J.D. and M. Black, 1982. Physiology and Biochemistry of Seeds. Berlin: Springler Verlag.

7. Hegarty T.W., 1978. The physiology of seed hydration and dehydration and the relation between water stress and the control of germination. A Review Plant Cell and Environment, 1: 101-119.

8. Szarejko, I. and M. Maluszynski, 1980. Analysis of Usefulness of Sodium Azide in Plant Breeding. Acta. Biol., 9: 60-66.

9. Savaskan, C. and M.C. Toker, 1991. Effects of Various Doses of Gamma Radiation on the Seed Germination and Root Tips Chromosomes of Rye (Secale cereale L.). Turk. J. Bot., 15: 349-359.

10. Lavender, E.A., 1992. Genotypic variation in the root system of Betula pendula. $\mathrm{PhD}$ Thesis. University of Aberdeen, Aberdeen.

11. Ciftci, C.Y., A.D. Turkan, K.M. Khawar, M. Atak and S. Ozcan, 2004. Use of Gamma Rays to Induce Mutations in Four Pea (Pisum sativum L.) cultivar. Turk. I. Biol., 30: 29-37. 